\title{
Primaquine double dose for 7 days is inferior to single-dose treatment for 14 days in preventing Plasmodium vivax recurrent episodes in Suriname
}

This article was published in the following Dove Press journal: Infection and Drug Resistance

\author{
M Sigrid Mac \\ Donald-Ottevanger ${ }^{1}$ \\ Malti R Adhin ${ }^{2}$ \\ Jeetendra Kumar Jitan ${ }^{3}$ \\ Gustavo Bretas ${ }^{4}$ \\ Stephen GS Vreden' \\ 'Foundation for Scientific Research \\ Suriname (SWOS), ${ }^{2}$ Department \\ of Biochemistry, Anton de Kom \\ University of Suriname, ${ }^{3}$ Department \\ of Public Health, Ministry of Health, \\ Paramaribo, Suriname; ${ }^{4}$ Independent \\ consultant, Rio de Janeiro, Brazil
}

\begin{abstract}
Background: Recurrent episodes of Plasmodium vivax are caused by dormant liver stages of the parasite, which are not eradicated by choloroquine. Therefore, effective treatment also includes the use of primaquine (PQ). However, this secondary preventive therapy is often not effective, mostly due to poor adherence to the relatively long treatment course, justifying a comparative study of the efficacy of different durations of PQ treatment.

Materials and methods: We included patients presenting with an acute and documented P. vivax infection from January 2006 to February 2008. All patients received chloroquine $25 \mathrm{mg} / \mathrm{kg}$ over a 3-day period. Subsequently, patients in group 7D received PQ $30 \mathrm{mg}$ /day for 7 days, and patients in group 14D received standard PQ $15 \mathrm{mg}$ /day for 14 days. All doses were given under supervision and patients were followed up for at least 6 months. The Kaplan-Meier method was used to estimate cumulative probability of recurrence up to 12 months after treatment initiation stratified by treatment group. Cox regression was used to assess possible determinants for recurrent parasitemia.

Results: Forty-seven of the 79 included patients (59.5\%) were allocated to group 7D and 32 patients $(40.5 \%)$ were allocated to group 14D. Recurrent parasitemia was detected in $31.9 \%$ of the cases in group 7D compared to $12.5 \%$ of the cases in group $14 \mathrm{D}$ (hazard ratio [HR] $=3.36$, 95\% CI 1.11-10.16). Cumulative probability for recurrent parasitemia at 3, 6, and 12 months was 0.201 (95\% CI 0.106-0.362), 0.312 (95\% CI 0.190-0.485), and 0.424 (95\% CI 0.274-0.615) for group 7D and 0.100 (95\% CI 0.033-0.279), 0.100 (95\% CI $0.033-0.279)$, and 0.138 (95\% CI $0.054-0.327$ ) for group $14 \mathrm{D}$, respectively. When adjusted for possible confounders, differences in recurrent parasitemia remained significant between the two regimens in Cox regression analysis. Conclusion: More than $30 \%$ of the patients receiving shorter treatment course had recurrent parasitemia, suggesting that the standard dose of $15 \mathrm{mg}$ /day PQ for 14 days is more efficacious than $30 \mathrm{mg}$ for 7 days in preventing $P$. vivax recurrent episodes. Furthermore, we suggest that $P$. vivax treatment in Suriname should be changed to PQ $30 \mathrm{mg} /$ day for 14 days, as per Center for Disease Control and Prevention recommendation, in light of a recurrence rate of over $10 \%$, even in group 14D.
\end{abstract}

Keywords: malaria, vivax, recurrent episode, primaquine, treatment duration, efficacy

\section{Introduction}

Worldwide, almost 2.5 billion people are at risk for a Plasmodium vivax infection. ${ }^{1}$ In the Americas, more than $70 \%$ of all malarial infections are caused by $P$. vivax, and morbidity is high due to frequent recurrent episodes. ${ }^{2}$ Recent data have shown a steep decline in cases of malaria since 2000, but still more than 148 million people in this region remain at risk for the disease. ${ }^{1,3}$
Correspondence: M Sigrid Mac
Donald-Ottevanger
Foundation for Scientific Research
Suriname (SWOS), Leysweg 49,
Paramaribo, Suriname
Email m.sigridmacdonald@gmail.com 
Among the five species of plasmodium that affect humans, only P. vivax and Plasmodium ovale have stages (hypnozoites) that remain dormant in the liver cells for lengthy periods of time before reactivating and invading the blood (relapse) weeks to months after the primary infection. ${ }^{4}$ The objective of treating $P$. vivax is to cure both the blood stage as well as the liver stage infection. Primaquine (PQ) is currently the only commercial antimalarial drug that combats hypnozoites in the liver. ${ }^{5}$

WHO currently recommends chloroquine (CQ) as the first-line treatment for $P$. vivax infection. ${ }^{6} \mathrm{In}$ areas with CQresistant $P$. vivax, artemisinin-based combination therapies containing piperaquine, mefloquine, or lumefantrine are the recommended treatments. ${ }^{6}$ For the prevention of relapses, PQ is so far the only approved drug. There are several PQ regimens in common use today. ${ }^{7}$ The currently recommended regimen for the cure of P. vivax by the WHO is CQ $25 \mathrm{mg}$ base/ $\mathrm{kg}$ over a 3-day period, followed by PQ $0.25 \mathrm{mg}-0.5 \mathrm{mg} / \mathrm{kg}$ bodyweight daily over a 14-day period. ${ }^{6}$ Usually, a simplified regimen of CQ $1500 \mathrm{mg}$ over a 3-day period is given, followed by $15 \mathrm{mg}$ of PQ per day for 14 days. Failure of this regimen can be due to a number of reasons, such as CQ resistance, ${ }^{8-10}$ intrinsic tolerance to $\mathrm{PQ},{ }^{11,12}$ reduced absorption, counterfeit drugs, and lack of compliance. ${ }^{13}$ Besides variation in drug susceptibility, factors such as rate and burden of hypnozoite carriage can also impact the disease outcome. ${ }^{14}$

There is a variance in recurrent episodes geographically and across $P$. vivax strains with the standard regimen. ${ }^{5,15} \mathrm{In}$ Colombia, Alvarez et al found a $17.6 \%$ recurrence rate when using the standard regimen. ${ }^{7}$ Therapy against the more tropic Chesson strain, frequently found in South-East Asia and Oceania, achieved only a $70 \%-80 \%$ efficacy, ${ }^{16,17}$ suggesting tolerance to the standard PQ therapy in those regions. In support of this theory, studies where a higher total dose was given for 14 days showed a higher efficacy than the standard treatment; therefore, a regimen of $30 \mathrm{mg}$ daily (which corresponds to $0.5 \mathrm{mg} / \mathrm{kg} /$ day) for 14 days in those regions is now widely recommended. . $^{16,18,19}$

Nonsupervised treatment has a higher rate of relapse than supervised treatment, ${ }^{13}$ suggesting that possible nonadherence leads to reduced effectiveness. Therefore, adherence to the treatment regimen is important in determining the efficacy of the treatment. Clyde et al have shown that $60 \mathrm{mg} /$ day for 7 days is equally effective as $30 \mathrm{mg} /$ day for 14 days, ${ }^{20}$ thereby suggesting that it is the total dose of PQ administered, rather than the duration of treatment, that determines efficacy. ${ }^{16,21,22}$

Shorter regimens would theoretically improve user compliance and acceptability if the total dose equals the dose proposed by the Center for Disease Control or the WHO. ${ }^{13,21}$ In some countries, such as Brazil, such a shorter, higher dose regimen is being implemented; PQ $0.5 \mathrm{mg} /$ day for 7 days is being used as the first-line treatment for $P$. vivax.$^{21}$ However, because of a higher rate of relapses due to subtherapeutic PQ doses in overweight patients, ${ }^{23}$ weight-adjusted PQ doses are recommended for patients weighing more than $70 \mathrm{~kg}$ in Brazil. ${ }^{24}$

The objective of the present study was to compare the efficacy of a total dose of $3.5 \mathrm{mg} / \mathrm{kg}$ in a 7-day regimen of 0.5 $\mathrm{mg} / \mathrm{kg} / \mathrm{day}$ (a maximum of $30 \mathrm{mg}$ per day) and the standard regimen of $0.25 \mathrm{mg} / \mathrm{kg} /$ day (maximum of $15 \mathrm{mg}$ per day) for 14 days, with a follow-up period up to a year. Restriction fragment length polymorphism analysis was used after polymerase chain reaction to attempt differentiation between possible new infections and true relapses. ${ }^{25}$

\section{Materials and methods}

The Suriname Ministry of Health's Ethics Committee (CMWO) granted ethical approval for this study. The study was an open, randomized "en blocque," prospective clinical controlled trial. The en-blocque method was used for practical reasons, which involved allocating patients from same households to the same group to prevent confusion in treatment among the patients (first 25 patients were allocated to group 1; next two blocks of 25 to group 2, and the following 25 to group 1 again). Initially, patients were recruited from Kwamala Samutu, an Amerindian village in the south of Suriname with high endemicity of $P$. vivax malaria. A sharp decline in the incidence of $P$. vivax in that region and the rest of the interior of Suriname, due to effective prevention strategies, necessitated additional recruitment of patients from the Urban Malaria Center in the capital, Paramaribo. Patients recruited from the Malaria Center usually traveled to regions within the interior often for work or vacation. Since Suriname is a relatively small country and with continuous transmission of $P$. vivax within the interior of Suriname, it is unlikely that $P$. vivax strains will not be equally distributed.

Inclusion criteria were a confirmed $P$. vivax infection (a positive thick blood smear), fever, or a history of fever $\left(\geq 37.5^{\circ} \mathrm{C}\right.$ axillary temperature). Patients had to be over 6 months of age, and signed informed consent had to be obtained from all patients, or parents or legal guardians of those under 18 years old. They had to be willing to attend follow-up for at least 6 months, maximum of 12 months. Reasons for exclusion included pregnancy, a history of antimalarial drug intake during the previous 2 weeks, concomitant infection with other plasmodium species, 
symptoms of severe malaria, other severe or chronic disease, hypersensitivity to antimalarial treatment, intolerance to the prescribed antimalarial treatment (vomiting), known positive glcose-6-phosphate dehydrogenase deficiency status, and consent withdrawal.

Patients in group 14D received CQ at $25 \mathrm{mg} / \mathrm{kg}$ over a period of 3 days, followed by the standard regimen of PQ for $P$. vivax, $0.25 \mathrm{mg} / \mathrm{kg} /$ day (maximum of $15 \mathrm{mg} /$ day) for 14 days, as recommended by the WHO. Patients in group 7D received the same regimen of CQ as in group 14D, followed by PQ $0.5 \mathrm{mg} / \mathrm{kg} /$ day (maximum of $30 \mathrm{mg} /$ day) for 7 days. PQ doses other than the standard $15 \mathrm{mg}$ dosage were prepared in capsule form by the Diakonessenhuis Hospital Pharmacy of Paramaribo, Suriname. All patients received direct observed treatment. Quality verification of the PQ tablets (Micro Labs $\mathrm{Ltd}^{\circledR}$, Bangalore, India) used during the study was performed on random PQ samples with the GPHF-MiniLab ${ }^{\circledR}$ system. $^{26}$

At the time of enrolment (day 0), blood was drawn from each patient for thick and thin blood smears, for dried blood spots on filter paper, and for a Binax $\mathrm{NOW}^{\circledR}$ Malaria rapid test (Binax, Inc., Portland, ME, USA). A complete clinical evaluation including medical history and physical examination was performed at inclusion. If indicated, patients also had to undergo a pregnancy test. Follow-up blood samples were obtained for thin and thick blood smears on days 7 and 14 and on the first workday of each month consecutively until 1 year after infection. Patients with recurrent parasitemia were treated with the standard regimen of CQ and PQ and were referred to the malaria program for further treatment management. The clinical evaluation, performed at enrolment, was repeated at each follow-up period. Patients who did not attend their scheduled appointment were actively followed up by one of the 12 fieldworkers involved in this study. Kwamala Samutu has a health clinic (medical post) in the village, facilitating the follow-up possibility of the locally recruited patients. In Paramaribo, the fieldworkers were instructed to actively follow up the patients not attending their follow-up schedule. If patients had recurrent parasitemia with $P$. vivax at 1 month, they were considered to have a possible CQ resistant $\operatorname{strain}^{27}$ and therefore not included in the recurrence analysis. Patients using other antimalarial treatment during the follow-up period were excluded as protocol violation.

Recrudescence analysis was performed on paired filter paper strips (Whatman $3 \mathrm{~mm}$ ) blotted with finger-prick blood from patients with recurring parasitemia. DNA was extracted from the blood spots on each filter using an adapted Saponin-Chelex protocol.$^{28}$ Primary master PCR amplification was performed for the two genes pvmsplF2, coding for merozoite surface protein1, and pvmsp $3 a$, coding for merozoite surface protein 3 alpha (both known to harbor repeat number and sequence polymorphisms), followed by a nested PCR. ${ }^{25,29}$ Detailed restriction patterns of the genes $p v m s p 3 a$ and $p v m s p 1 F 2$ were attained by digesting with two restriction enzymes: AluI/HhaI ( $v v m s p 3 a$ ) and AluI/MnlI (pvmsp1F2). Recurrent infections displaying deviations in one or more of the four restriction patterns were considered heterologous infections, while identical restriction profiles (or mixed patterns containing the initial and another genotype) were designated as homologous infections.

Descriptive statistics, chi-square and Mann-Whitney tests, were used to compare baseline characteristics between the two treatment groups. Kaplan-Meier method was used to estimate cumulative probability of recurrence up to 12 months after treatment initiation stratified by treatment group. Cox proportional hazards regression models were used to assess possible determinants for recurrent $P$. vivax parasitemia. Weight was dichotomized into $\leq 60 \mathrm{~kg}$ versus $>60 \mathrm{~kg}$, as treatments are officially weight based, yet simplification of this regimen was based on a person weighing $60 \mathrm{~kg}$. Weight was forcibly entered into the final model to assess as a possible confounder. Analyses were done using SPSS package version 22.0 (SPSS Inc., Chicago, IL, USA) and STATA version 11.2 (College Station, TX, USA).

\section{Results}

\section{Patient characteristics}

A total of 85 patients were enrolled from January 2006 till February 2008. Among them, 79 could be included for further analysis: 47 patients in group 7D (59.5\%) and 32 patients in group 14D (40.5\%). Approximately, 77.0\% (47/61) of the patients from recruitment center Paramaribo were allocated to group 7D and $23.0 \%$ to group 14D. All patients $(n=18)$ from Kwamala Samutu were allocated to group 14D. Patient characteristics are shown in Table 1. In both groups there were more males than females, $68.1 \%$ in group 7D and $63.3 \%$ in group $14 \mathrm{D}(p=0.805)$. Median age (interquartile range) in groups 7D and 14D was 30.0 years (21.0-37.0) and 21.0 years (13.0-25.0), respectively, $(p=0.002)$. Weight differed between both the groups; median weight in group 7D was $61.5 \mathrm{~kg}(54.3-70.8)$ and in group 14D was $59.0 \mathrm{~kg}$ $(41.0-66.0)(p=0.086)$.

\section{Recurrent parasitemia}

In group 7D, 31.9\% $(\mathrm{n}=15)$ had recurrent parasitemia compared to $12.5 \%$ in group $14 \mathrm{D}(\mathrm{n}=4)(p=0.032)$. Cumulative probability for recurrent parasitemia at 3,6 , and 12 months 
was 0.201 (95\% CI 0.106-0.362), 0.312 (95\% CI 0.1900.485 ), and 0.424 (95\% CI $0.274-0.615$ ) for group $7 \mathrm{D}$ and 0.100 (95\% CI $0.033-0.279), 0.100$ (95\% CI 0.033-0.279), and $0.138(95 \% \mathrm{CI} 0.054-0.327)$ for group $14 \mathrm{D}$, respectively. These results are represented in Figure 1. Analysis showed that the standard simplified regimen $15 \mathrm{mg} P Q$ per day for 14 days and $30 \mathrm{mg} /$ day for 7 days was inadvertently below the recommended $3.5 \mathrm{mg} / \mathrm{kg}$ total dose in the majority of patients in both the groups.

\section{Determinants of recurrent parasitemia}

The HR for recurrent parasitemia in the shorter duration treatment group (7D) was significantly higher than the longer treatment duration group (14D) $(\mathrm{HR}=3.4 ; 95 \% \mathrm{CI} 1.1-10.2)$. Sex, age, and weight were not associated with parasitemia recurrence (Table 2). Adjusting for weight in the final model, only shorter duration treatment remained significantly associated with parasitemia recurrence $(\mathrm{HR}=5.2 ; 95 \% \mathrm{CI} 1.5-18.1)$.

\section{Recrudescence analysis}

Recrudescence analysis could be performed on 14 of the 19 recurrent infections. In group 7D, 54.5\% (6/11) of the

Table I Baseline characteristics of patients using primaquine single dose for 14 days and double dosage for 7 days for radical cure of Plasmodium vivax

\begin{tabular}{|c|c|c|c|}
\hline Characteristics & $\begin{array}{l}\text { Group I4D } \\
\text { (I4 days) }\end{array}$ & $\begin{array}{l}\text { Group 7D } \\
\text { (7 days) }\end{array}$ & $p$-value \\
\hline $\mathrm{n}$ & 28 & 35 & 0.599 \\
\hline $\mathrm{M} / \mathrm{F}$ ratio & 0.6 & 0.7 & \\
\hline $\begin{array}{l}\text { Median age (IQR) } \\
\text { (years) }\end{array}$ & $21.0(13.3-25.8)$ & $32.0(22.0-40.0)$ & $<0.001$ \\
\hline $\begin{array}{l}\text { Median weight }{ }^{a} \\
(\mathrm{IQR})(\mathrm{kg})\end{array}$ & $60(42.0-66.0)$ & $64(55.0-75.1)$ & 0.007 \\
\hline
\end{tabular}

Note: aMissing data for weight, $n=2$.

Abbreviation: IQR, interquartile range.

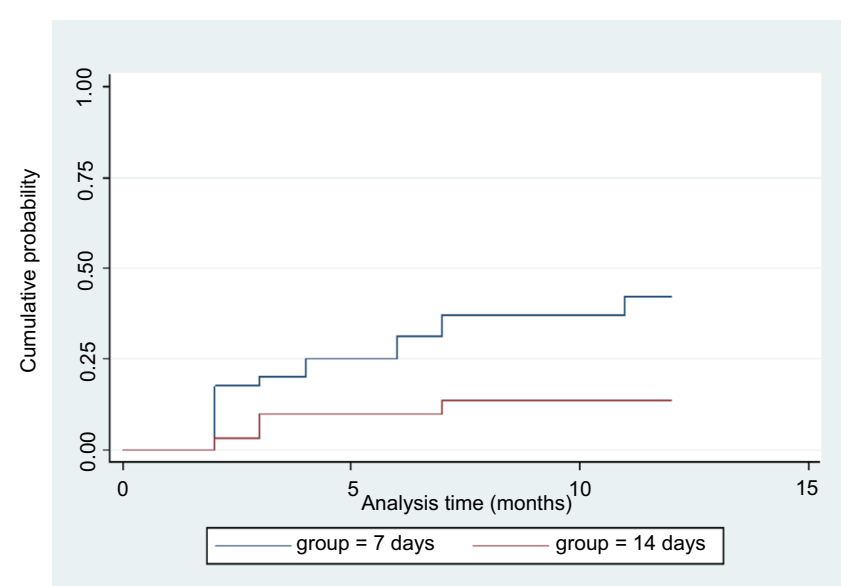

Figure I Cumulative probability of recurrent parasitemia recurrent infections were homologous infections when compared to the parasite present at inclusion. In group14D, $100 \%(3 / 3)$ of the infections were homologous $(p=0.231)$. The longest relapse period observed for the homologous infections was 7 months.

Statistical analysis of the efficacy of the two regimens taking homologous and heterologous infections into account was not possible, due to the limited numbers in each category and the fact that heterologous cases considered as new infections can also be true relapses displaying genetic differences originating from the hypnozoites.

\section{Discussion}

We found a higher incidence of recurrent parasitemia in group 7D (PQ $30 \mathrm{mg} /$ day for 7 days) than in group 14D ( $15 \mathrm{mg}$ PQ daily for 14 days), $p<0.05$. There are numerous studies evaluating different treatment regimens. For decades, the generally accepted view has been that the total dose, rather than the duration of treatment, influenced the prevention of recurrent episodes, ${ }^{4}$ which was largely based on a preclinical study in 1977 by Schmidt et al ${ }^{30}$ and a clinical study by Clyde et al in $1977 .{ }^{20}$ The latter study showed an effective prevention of recurrences in patients using $60 \mathrm{mg} /$ day over a period of 7 days. The follow-up period was adequate, and 8 of the 11 patients were followed up for at least 7 months, yet the number of patients in that specific study was small $(\mathrm{n}=11)$. A more recent study by Krudsoord et al compared a regimen comprising $30 \mathrm{mg}$ bid for 7 days to a regimen comprising $30 \mathrm{mg}$ qd for 11 and 14 days. ${ }^{17}$ There was no difference between the two groups, thus supporting the total dose theory. However, their follow-up period was a mere 30 days, excluding late recurrences. On the other hand, a study conducted in Peru reported similar recurrence rates in groups with a 7-day regimen of $0.5 \mathrm{mg} / \mathrm{kg} /$ day and with $0.25 \mathrm{mg} / \mathrm{kg} /$ day (maximum of $15 \mathrm{mg}$ per day) for 14 days. ${ }^{31}$ A study by Alving et $\mathrm{al}^{32}$ and a more recent study by Leslie et $\mathrm{al}^{33}$ showed that a regimen of a once-weekly dose of $45 \mathrm{mg}$ / week and $0.8 \mathrm{mg} / \mathrm{kg} /$ week of PQ, respectively, for 8 weeks was just as effective for radical cure of $P$. vivax as $0.5 \mathrm{mg} /$ $\mathrm{kg}$ /day for 14 days. Our results are in concordance with a study by Rajgor et al from India in 2003, which demonstrates higher recurrence and relapse rates in the group with 7 days double dose as compared to 14 days single dose. ${ }^{34} \mathrm{~A}$ Cochrane database systemic review published in 2013 did not find enough evidence to promote a different regimen than single-dose PQ for 14 days. ${ }^{35}$ Our findings add to the data, which fuel the debate about the most efficacious PQ regimen to prevent recurrence. 
Table 2 Bivariable and multivariable logistic regression analysis of possible determinants associated with Plasmodium vivax relapses among the study population in Suriname (2006-2008)

\begin{tabular}{|c|c|c|c|c|c|c|}
\hline Determinants & $\begin{array}{l}\text { Relapse, } \\
N=19, \text { n (\%) }\end{array}$ & $\begin{array}{l}\text { No relapse, } \\
\mathrm{N}=44, \mathrm{n}(\%)\end{array}$ & $\begin{array}{l}\text { Bivariable OR } \\
(95 \% \mathrm{Cl})\end{array}$ & p-value & $\begin{array}{l}\text { Multivariable } \\
\text { OR }(95 \% \mathrm{Cl})\end{array}$ & $p$-value \\
\hline Sex & & & & 0.177 & & 0.103 \\
\hline Male & $10(52.6)$ & $31(70.5)$ & 1 & & I & \\
\hline Female & $9(47.4)$ & I $3(29.5)$ & $2.2(0.7-6.5)$ & & $2.8(0.8-9.3)$ & \\
\hline Age category (years) & & & & 0.309 & & \\
\hline$\leq 19$ & $3(15.8)$ & I5 (34.I) & 1 & & & \\
\hline $20-39$ & II (57.9) & $22(50.0)$ & $2.5(0.6-10.5)$ & & & \\
\hline$\geq 40$ & $5(26.3)$ & 7 (I5.9) & $3.6(0.7-19.3)$ & & & \\
\hline Weight $(\mathrm{kg})^{\mathrm{a}}$ & & & & 0.263 & & \\
\hline$\leq 60$ & $7(36.8)$ & $22(52.4)$ & 1 & & & \\
\hline$>60$ & $12(63.2)$ & $20(47.6)$ & $1.9(0.6-5.7)$ & & & \\
\hline Treatment duration & & & & 0.019 & & 0.013 \\
\hline 7 days & $15(78.9)$ & $20(45.5)$ & $4.5(1.3-15.8)$ & & $5.3(1.4-19.6)$ & \\
\hline 14 days & $4(2 I . I)$ & $24(54.5)$ & 1 & & 1 & \\
\hline
\end{tabular}

Notes: aMissing data for weight, $n=2$. Statistically significant values are indicated in bold.

Abbreviations: OR, odds ratio; $95 \% \mathrm{Cl}, 95 \%$ confidence interval.

Our study has some limitations. First of all, the study findings date from 2006 to 2008, but the data are still relevant since PQ is so far the only approved drug for the prevention of P.vivax relapses, ${ }^{6}$ and several countries, including our neighbor Brazil, still use the short regimen. Second, the number of patients in both groups is small. This study was initiated in the period in which the number of malaria cases started to drastically decline due to novel control strategies. ${ }^{36}$ Also, the randomization was weakened, since the local circumstances in the village Kwamala Samutu dictated the use of one treatment within the same "house" in the same period, but fortunately, this did not significantly influence the outcome. Furthermore, the number of recurrent episodes was low, therefore complicating comparisons, besides the inadequacy of current molecular methods to distinguish between a true recrudescence of the initial infection or a relapse from hypnozoites generated from the prior blood stage infection. Last, the therapeutic dose in both the groups was suboptimal if the actual bodyweight was taken into account. However, statistical analysis showed that this did not influence recurrent parasitemia cases.

\section{Conclusion}

In summary, general analysis showed a significantly higher incidence of recurrent parasitemia in group 7D $(p<0.05)$, suggesting that the duration of the treatment is, in fact, more important than the total dose. Heavier weight, resulting in possible subtherapeutic doses, was not identified as a confounder. Since the recurrence of parasitemia was higher than $10 \%$ even in group 14D and the majority of patients in our study received subtherapeutic doses, replacing the current standard dose of $15 \mathrm{mg}$ per day for adults by an accurately calculated dose of $15 \mathrm{mg} / \mathrm{kg}$ of bodyweight or prescribing the $30 \mathrm{mg} /$ day regimen, already implemented in Thailand and other countries in South- East Asia, is recommended.

\section{Acknowledgments}

The authors acknowledge Dr Jannie van der Helm for support with the statistical analysis.

This study was supported by United States Agency for International Development through the Amazon Malaria Initiative.

\section{Disclosure}

The authors report no conflicts of interest in this work.

\section{References}

1. Gething PW, Elyazar IRF, Moyes CL, et al. A long neglected world malaria map: Plasmodium vivax endemicity in 2010. PLoS Negl Trop Dis. 2012;6(9):e1814.

2. Regional Profiles. World Malaria Report. World Health Organization. Available from: http://www.who.int/malaria/publications/worldmalaria-report-2015/wmr2015-profiles.pdf. Accessed June 4, 2016.

3. WHO Library Cataloguing-in-Publication Data. Control and Elimination of Plasmodium vivax Malaria: A Technical Brief. Available from: http://www.who.int/malaria/publications/world-malaria-report-2015/ wmr2015 /. Accessed June 4, 2016.

4. Cogswell FB. The hypnozoite and relapse in primate malaria. Clin Microbiol Rev. 1992:5(1):26-35.

5. Baird KJ, Maguire JD, Price RN. Diagnosis and treatment of Plasmodium vivax malaria.. Adv Parasitol. 2012;80:203-70.

6. WHO. Guidelines for the treatment of malaria. 3rd edition. Geneva: World Health Organization; 2015. Available from: http://apps.who. int/iris/bitstream/10665/162441/1/9789241549127_eng.pdf?ua=1. Accessed December 29, 2015

7. Alvarez G, Pineros J, Tobon A, et al. Efficacy of three chloroquineprimaquine regimens for treatment of Plasmodium vivax malaria in Colombia. Am J Trop Med Hyg. 2006;75(4):605-609.

8. Murphy GS, Basri H, Purnomo MS, et al. Vivax malaria resistant to treatment and prophylaxis with chloroquine. Lancet. 1993;341(8837):91-100. 
9. Than M, Kyaw MP, Soe AY, Gyi KK, Sabai M, Oo M. Development of resistance to chloroquine by Plasmodium vivax in Myanmar. Trans $R$ Soc Trop Med Hyg. 1995;89(3):307-308.

10. Soto J, Toledo J, Gutierrez P, et al. Plasmodium vivax clinically resistant to chloroquine in Colombia. Am J Trop Med Hyg. 2001;65(2):90-93.

11. Bunnag D, Karbwang J, Thanavibul A, et al. High dose of primaquine in primaquine resistant vivax malaria. Trans $R$ Soc Trop Med Hyg. 1994;88:218-219.

12. Wilairatana P, Silachamroon S, Krudsoord S, et al. Efficacy of primaquine regimens for primaquine-resistant plasmodium vivax malaria in Thailand. Am J Trop Med Hyg. 1999;61(6):973-977.

13. Baird JK, Rieckmann, KH. Can primaquine therapy for vivax malaria be improved. Trends Parasitol. 2003;19(3):115-120.

14. Imwong M, Snounou G, Pukrittayakamee S, et al. Relapses of Plasmodium vivax infection usually result from activation of heterologous hypnozoites. J Infect Dis. 2007;195: 927-933.

15. Goller JL, Jolley D, Ringwald P, Biggs B. Regional differences in the response of Plasmodium vivax malaria to primaquine as anti-relapse therapy. Am J Trop Med Hyg.2007;76(2):203-207.

16. Bunnag D, Karbwang J, Thanavibul A, et al. High dose of primaquine in primaquine resistant vivax malaria. Trans $R$ Soc Trop Med Hyg. 1994;88:218-219.

17. Krudsoord S, Tangpukdee N, Wilairatana P, et al. High-dose primaquine regimens against relapse of Plasmodium vivax malaria. Am J Trop Med Hyg. 2008;78(5):736-740.

18. Dao NVH, Cuong BT, Ngoa ND. Vivax malaria preliminary observations following a shorter course of treatment with artesunate plus primaquine. Trans $R$ Soc Trop Med Hyg. 2007;101:534-539.

19. Centers for Disease Control and Prevention. Treatment of Malaria (Guidelines For Clinicans). Available from: http://www.cdc.gov/ malaria/resources/pdf/treatmenttable.pdf Accessed June 4, 2016.

20. Clyde DF, McCarthy VC. Radical cure of Chesson strain vivax malaria in man by 7 , not 14, days of treatment with primaquine. Am JTrop Med Hyg. 1977;26: (3):562-563.

21. Ferreira M, Castro MC. Challenges for malaria elimination in Brazil. Malar J. 2016; 15:284.

22. John GK, Douglas NM, von Seidlein L, et al. Primaquine radical cure of Plasmodium vivax: a critical review of the literature. Malar J. 2012;11: 280. Available from: http://doi.org/10.1186/1475-2875-11280. Accessed December 29, 2015.

23. Duarte EC, Pang LW, Ribeiro LC, Fontes CJF. Association of subtherapeutic dosages of a standard drug regimen with failures in preventing relapses of vivax malaria. Am J Trop Med Hyg. 2001;65(5):471-476.
24. Brasil. Ministério da Saúde. Secretaria de Vigilância em Saúde. Departamento de Vigilância Epidemiológica. Guia prático de tratamento da malária no Brasil. Brasília: Ministério da Saúde, 2010:36. [Portugese]

25. Imwong M, Pukrittayakamee S, Grüner AC, et al. Practical PCR genotyping protocols for Plasmodium vivax using Pves and Pvmsp1. Malar J;2005;4(1):20.

26. The GPHF-Minilab ${ }^{\circledR}$. Protection against counterfeited and substandard pharmaceuticals. Available from: www.gphf.org/web/en/minilab. Accessed June 4, 2016.

27. Baird JK, Leksana B, Masbar S, et al. Diagnosis of resistance to chloroquine by Plasmodium vivax: timing of recurrence and whole blood chloroquine levels. Am J Trop Med Hyg. 1997;56:621-626.

28. Foley M, Ranford-Cartwright LC, Babiker HA. Rapid and simple method for isolating malaria DNA from fingerprick samples of blood. Mol Biochem Parasitol. 1992;53(1-2):241-244.

29. Bruce MC, Galinski MR, Barnwell JW, Snounou G, Day KP. Polymorphism at the merozoite surface protein-3alpha locus of Plasmodium vivax: global and local diversity. Am J Trop Med Hyg. 1999:6(4): $518-525$.

30. Schmidt LH, Fradkin R, Vaughan D, Rasco J. Radical cure of infections with Plasmodium cynomolgi: a function of total 8-aminoquinoline dose. Am J Trop Med Hyg. 1977;26:1116-1128.

31. Durand S, Cabezas C, Lescano AG, et al. Efficacy of three different regimens of primaquine for the prevention of relapses of Plasmodium vivax malaria in the Amazon Basin of Peru. Am J Trop Med Hyg. 2014;91(1): 18-26.

32. Alving AS, Johnson CF, Tarlov AR, Brewer GJ, Kellermeyer RW. Mitigation of the haemolytic effect of primaquine and enhancement of its action against exoerythrocytic forms of Chesson strain of Plasmodium vivax by intermittent regimens of drug administration. Bull WHO. 1960;22:621-631.

33. Leslie T, Mayan I, Mohammed N, Erasmus P, Kolaczinski J. A randomised trial of an eight-week, once weekly primaquine regimen to prevent relapse of Plasmodium vivax in Northwest Frontier Province, Pakistan. PLoS One. 2008;3(8): e2861.

34. Rajgor DD, Gogtay NJ, Kadam VS, et al. Efficacy of a 14-day primaquine regimen in preventing relapses in patients with Plasmodium vivax malaria in Mumbai, India. Trans R Soc Trop Med Hyg. 2003;97(4):438-40.

35. Galappaththy GN, Tharyan P, Kirubakaran R. Cochrane Database Syst Rev. 2013;(10):CD004389.

36. Hiwat H, Hardjopawiro L, Takken W, Villegas L. Novel strategies lead to pre-elimination in previously high-risk areas in Suriname, South America. Malar J. 2012;11(1):10.
Infection and Drug Resistance

\section{Publish your work in this journal}

Infection and Drug Resistance is an international, peer-reviewed openaccess journal that focuses on the optimal treatment of infection (bacterial, fungal and viral) and the development and institution of preventive strategies to minimize the development and spread of resistance. The journal is specifically concerned with the epidemiology of antibiotic

\section{Dovepress}

resistance and the mechanisms of resistance development and diffusion in both hospitals and the community. The manuscript management system is completely online and includes a very quick and fair peerreview system, which is all easy to use. Visit http://www.dovepress.com/ testimonials.php to read real quotes from published authors. 